\title{
Mysticism without concepts
}

\section{Sebastian Gäb ${ }^{1}$ (iD}

Received: 2 March 2021 / Accepted: 21 April 2021 / Published online: 23 April 2021

(c) The Author(s) 2021

\begin{abstract}
It has often been claimed, e.g. by William James or Aldous Huxley, that mystical experiences across times and cultures exhibit a striking similarity. Even though the words and images we use to describe them are different, underneath the surface we find a common experiential core. Others have rejected this claim and argued that all experiences are intrinsically shaped by the mystics' pre-existing religious concepts. Against these constructivist objections, I defend the idea of a common core by arguing that even if all experience is interpreted through concepts, there could still be a common core. Those who reject the common core thesis usually argue that no distinction between experience and interpretation can be made since all experience is per se already interpreted. The notion of an uninterpreted experience is self-defeating. Drawing on current research on nonconceptual mental content, I argue (a) that experiences can have nonconceptual content; (b) that interpretation must be understood as conceptualization and (c) that conceptualization presupposes a raw mental content that is not conceptualized. This raw content is not experienced as nonconceptual. Rather, the nonconceptual, uninterpreted common core is an abstraction which shows itself only through reflection. Thus, the existence of a common core is compatible with the fact that all experiences are interpreted.
\end{abstract}

Keywords Mysticism · Religious experience $\cdot$ Nonconceptual content · Constructivism $\cdot$ Perennialism

It has often been claimed that mystical experiences across times and cultures appear to be strikingly similar. The words and metaphors used to describe them may vary, but at their core, these experiences are always the same, everywhere. In William James' famous words:

In mystic states we both become one with the Absolute and we become aware of our oneness. This is the everlasting and triumphant mystical tradition,

Sebastian Gäb

s.gaeb@1mu.de

1 Faculty of Philosophy, LMU Munich, Munich, Germany 
hardly altered by differences of clime or creed. In Hinduism, in Neoplatonism, in Sufism, in Christian mysticism, in Whitmanism, we find the same recurring note, so that there is about mystical utterances an eternal unanimity which ought to make a critic stop and think, and which brings it about that the mystical classics have, as has been said, neither birthday nor native land. ${ }^{1}$

This claim-that mystical experiences have a common, invariable core unaffected by the mystic's linguistic, cultural or religious background-is usually called the common core thesis. ${ }^{2}$ Other than James, writers like Aldous Huxley or Walter Stace have defended it emphatically, while others have rejected with equal emphasis, saying that it papers over the differences between various traditions and ignores the importance of the cultural setting in which these experiences happen. To these critics, the common core thesis is not an interpretation of actual mystical experiences but a thinly veiled plea for a pantheist or pluralist unification of all religions. My aim in this paper is to defend the common core thesis against its critics: first, by arguing that we have reason to believe it to be true, and second, by explaining how the thesis should be understood so it isn't affected by these criticisms. More precisely, I will first sketch briefly what I mean by 'mystical experiences'; next, I will say why the common core thesis matters, or rather, why we should be interested in whether or not it is true; then, I will discuss some psychological and neurological evidence in favor of the common core thesis; finally, I will discuss the crucial philosophical question: how could the common core thesis be true? What kind of theoretical framework do we need to make sense of it?

\section{Mystical experience}

To begin with, just a word about what I mean by 'mystical experiences'. The term 'mystical' is notoriously tricky and tends to evoke a lot of mixed associations, not all of them favorable. Moreover, there is no consensus in the scholarly literature on what 'mysticism' exactly means, and the term is commonly used for a large variety of phenomena. My understanding of the term 'mystical' in this paper is rather narrow: I will employ it to denote a certain subset of religious or spiritual experiences - not all religious experiences are mystical or contain a mystical element. Mystical experiences as a type have a certain idiosyncratic phenomenology although the individual experiences differ vastly. Roughly, I believe the following four elements are sufficient for an approximate understanding of what mystical experiences might be ${ }^{3}$ :

\footnotetext{
1 James (2002): 324f.

2 Occasionally, the term 'perennialism' is used, too, drawing on Huxley's famous book The perennial philosophy. Still, I would prefer to make a slight distinction between these two: while the common core thesis merely claims that mystical experiences are phenomenologically the same (at the level of pure experience), it does not entail that all mystics share a set of higher-order beliefs about these experiences. The common core thesis is not a perennial philosophy because it is not a philosophy in the first place.

3 There is large debate on how to characterize and categorize mystical experiences, beginning with James (2002): 295. The most influential list comes from Stace (1961): 79/110. See also Wainwright (1981): 1-18 for a similar approach and Marshall (2005), ch. 2 for an overview of available typologies. I will set these issues aside here in the hope that you will get an idea of what I have in mind when I speak
} 
(1) Mystical experiences are unitive. The mystic has a sense of being one with God, the universe, or nature. In some experiences, all things are perceived as one. In others, the mystic's mind is completely empty, and the distinction between self and other, or subject and object, loses its sense.

(2) Mystical experiences are noetic. This means they are not merely feelings but have some kind of cognitive content. The mystics believe themselves in contact with objective reality, more real than the reality we encounter in everyday life. Thus, mystical experiences are epistemically relevant: it appears as if something is seen or grasped in these experiences, although the mystics often have trouble explaining what. They claim their insights to be ineffable and often resort to metaphors like emptiness or darkness.

(3) Mystical experiences have no specific content. They are not perceptions of religious entities (so visions or hearing voices wouldn't count as mystical experiences in this sense of the term). ${ }^{4}$ Of course, not all mystical experiences are objectless (meaning that the mystic loses all awareness of external objects); so-called extrovertive mystical experiences are characterized by a sense of union with the natural world, and of course these experiences involve external objects. Yet, these objects are not essential to the experience. What makes the experience mystical is not its object, but the mode in which the object is experienced. Mystical experiences might therefore best be characterized as a certain kind of altered state of consciousness. To understand them, we need to understand how being mystically conscious is different from being conscious the ordinary way.

(4) Mystical experiences have a certain intense emotional quality. The mystics are washed over with feelings of love and awe, peace, bliss, and joy.

Note that this description is purely phenomenological, i.e. the mystical experience is identified merely by what it feels like. Whether these experiences are veridical or not, is a wholly different question. This characterization of mystical experiences in no way requires us to postulate some religious reality which the mystic encounters. And neither is there any reason to exclude experiences from this definition simply because they might have a natural cause (e.g. shifts in brain chemistry, or psychedelic drugs). All that matters are the experiences themselves.

\footnotetext{
Footnote 3 (continued)

of mystical experiences - something like this - although I cannot fully explicate what 'this' is. For an account of how mystical experiences fit into the wider category of religious experience, see Franks Davis (1989): 39ff.

${ }^{4}$ Others, e.g. Alston 1991, use the term differently to mean precisely some kind of quasi-perceptive experience of divine entities, not unlike sense experience of ordinary objects. There is no point in arguing which meaning is the 'correct' one; I simply note that he and I aren't talking about the same thing.
} 


\section{Why it matters}

If there actually is a common core, why does it matter for philosophy of religion? There are two reasons why I believe we should be interested in whether the common core thesis is true: one metaphysical and one epistemological. The metaphysical reason is that the common core thesis supports religious pluralism, especially as Hick thought of it. If the common core thesis is true, this is evidence that some form of religious pluralism might be true. Hick proposes his famous pluralistic hypothesis: that there is a single common reality behind all the world's major religious traditions which he calls the Real. ${ }^{5}$ But we encounter the Real only in experiences shaped by our various cultural and religious backgrounds. Our cultural schemes act like a filter preventing us from experiencing the Real in itself. All we have is the Real in its cultural disguises. So, when a Buddhist experiences the non-personal state of jhana and a Christian experiences the state of union with a personal God, they both encounter the Real-their experiences contradict each other only on the surface. The mutually exclusive predicates 'personal' and 'non-personal' only apply to the different appearances of the Real, not the Real itself.

Now, how could we decide whether Hick's pluralistic hypothesis is actually true? One important factor in deciding whether a hypothesis is true or at least probable is its explanatory power. A hypothesis has high explanatory power if some piece of evidence becomes more probable (or is more to be expected) assuming the hypothesis is true. A good hypothesis will explain pieces of evidence which would otherwise remain puzzling or inexplicable. For example, the hypothesis that Jones is the murderer has high explanatory power with regard to the fact that Jones's fingerprints have been found on the gun: if the hypothesis is true, we should expect this; if it is false, the evidence is hard to explain.

If the pluralistic hypothesis is correct, what kind of mystical experiences should we expect? According to Hick, they are all experiences of the same reality, so they should show at least some identical core properties. But they are also shaped by different conceptual and cultural schemes, so we should also expect them to be not completely identical-there ought to be differences in the words and images we use to describe these experiences, depending on our cultural backgrounds. But this is just what the common core thesis states. If there actually is a common core in mystical experiences, this is a surprising fact that needs to be explained. The pluralistic hypothesis offers a good explanation, because according to pluralism, a common core is precisely what we should expect to find. Thus, the existence of the common core is a good reason to believe in pluralism, since it raises pluralism's explanatory power. To be sure, this just means that pluralism is a good explanation for the existence of a common core, but it is by no means the only and maybe not even the best one. There could be other explanations-which, too, would gain in explanatory power. A common core just makes pluralism overall more probable. The existence of a common core won't allay all doubts we might have about pluralism, but

\footnotetext{
5 Hick (2004): ch. 14.
} 
in connection with other evidence it could still be part of a larger, cumulative case argument in its favor.

The second reason is an epistemological one: if the common core thesis is true, this raises the credibility of religious experience. Experience is generally one of the most important sources of knowledge we have. Most of what we know about reality, we know from experience. So, prima facie it seems that mystical experience should be epistemically relevant, too. But, of course, not every experience is credible-sometimes we need to make sure we can trust this particular experience. One fundamental objection is: mystical experiences aren't credible because they aren't evidence for anything beyond themselves unless we have additional independent reasons to believe them to be true. ${ }^{6}$ If a mystic experiences oneness with God, then this is no reason to believe that there is a God unless we have other reasons to think so. Mystical experiences can confirm what we have reason to believe anyway, but they cannot by themselves establish the credibility of some claim. Against this, it can be argued that nobody would have standards this high for the credibility of any other form of experience. We accept experience as a reliable source of knowledge in our everyday life and naturally believe that our own experiences as well as those of others are usually trustworthy, if we have no explicit reasons to doubt them. If I believe that my neighbor plays the guitar, all I need to justify this belief is to say that I saw him play the guitar. There is no need to further justify the credibility of my experiences. This is a basic principle of rationality Richard Swinburne has dubbed the principle of credulity $(P C)$ :

I suggest that it is a principle of rationality that (in the absence of special considerations), if it seems (epistemically) to a subject that $\mathrm{x}$ is present (and has some characteristic), then probably $\mathrm{x}$ is present (and has some characteristic); what one seems to perceive is probably so. ${ }^{7}$

Of course, this principle holds only ceteris paribus, i.e. in the absence of relevant defeaters. There are two kinds of defeaters: (a) objective defeaters: what I seem to perceive is probably false (e.g. if I believe that I saw Immanuel Kant on the subway); (b) subjective defeaters: the conditions of my experience make me unreliable (e.g. if I believe that I saw a tiger in my bedroom, but I have a diagnosed psychosis). The PC doesn't say that all experiences are credible; it just says that every experience is innocent until proven guilty. Experiences are credible as long as we have no reason to doubt their credibility. The principle shifts the burden of proof: not the one who has the experience needs to prove that it is credible, the one who doubts it needs to prove that it is not.

This holds for mystical experiences, too: they are credible, unless they are not. But there's the rub: is there really no reason to doubt the credibility of mystical experiences? Various objections have been raised: mystical experiences are merely the result of pathological mental conditions; they can never be verified; there are no standards by which we might judge their reliability; there is no way to link the

\footnotetext{
${ }^{6}$ E.g. Flew (2005): 134.

7 Swinburne (2004): 303.
} 
contents of such an experience to the contents of our religious beliefs. ${ }^{8}$ But the gravest objection is this: there is a variety of very diverse yet mutually inconsistent mystical experiences-they can't all be true.

Contradictory experiences are usually a strong indication that there is something off. Obvious contradictions between two experiences cast severe doubt on their reliability. If three witnesses of a traffic collision give three inconsistent reports of what happened, the reasonable thing to do is not to believe any of them until further evidence comes up. Coherent reports, on the other hand, mutually affirm each other's credibility. But if we compare mystical experiences across different religions and cultures, we will find that their contents seem to be quite heterogeneous and not at all consistent with each other: there are experiences of union with a theistic God, of being one with emptiness, with a cosmic soul, or with nature. This indisputable diversity poses two problems for the claim that religious experiences are credible: (a) the problem of consistency - at least some mystical experience cannot be veridical for purely logical reasons. If two experiences contradict each other, only one of them may be true (or none). (b) the problem of contingency - mystical experiences seem to always reflect the prior beliefs of those who have them. Catholics have experiences of union with God, Zen Buddhists of emptiness; Apollo appears in Delphi, but not in Birmingham. If it is really one and the same reality we encounter in mystical experiences, why does it seem to depend on the contingent conditions of these experiences? The common core thesis holds the potential for an effective rejoinder to this objection. If there is a common core, mystical experiences don't actually contradict each other and (according to the PC) should not be considered as in principle untrustworthy. And if the common core is just a common core surrounded by a cluster of concepts and images of the mystic's respective tradition, then there is no need to be alarmed by the fact that descriptions of mystical experiences always reflect prior beliefs. Why wouldn't they?

\section{The empirical case for the common core thesis}

The common core thesis has mostly been discussed from a theoretical vantage point. In recent years though, it has been the focus of empirical investigations delivering some interesting evidence for its truth. The first case comes from the work of Ralph Hood. Hood, a specialist in psychology of religion, has developed a mysticism scale (based on the criteria detailed in Stace, 1961) which allows measuring the intensity and quality of an experience's mystical character by assessing the reports of persons who claim to have such experiences. Applying this scale, Hood and his collaborators have conducted a vast amount of surveys on mystical experiences in the general population of several different countries. The scale comprises two factors, one focused on the quality of experience (introvertive or extrovertive), the other on the religious interpretation of the experience. The scale then measures assent or dissent to statements like 'I have had an experience in which I realized the oneness

\footnotetext{
${ }^{8}$ For an overview of these standard objections, see Davies (2004): chapter 6.
} 
of myself with all things' or 'I have had an experience in which all things seemed to be conscious'. 9 After several decades of research in a variety of socio-cultural settings, Hood has reached an unambiguous conclusion: the ratio of assent to the statements in question is fairly constant and doesn't depend on the vocabulary used or the cultural context of the respondents. Persons who claim to have had a mystical experience tend to describe it consistently in terms of the factors delineated by Stace and Hood. There is no significant difference whether a neutral language is used and one simply asks about an experience of some kind of ultimate reality, or whether the experience is interpreted in Christian terms as an encounter with God or Christ. ${ }^{10}$ Neither does the religious affiliation of the respondents matter. The results are practically the same for American Christians and Iranian Muslims-both groups of subjects describe their experiences in terms of unity, timelessness, or ineffability. These items also have more or less the same degree of correlation in both countries, which means that the core characteristics of mystical experiences are not only the same regardless of the particular culture or religion, they also are mutually dependent and don't occur separately. ${ }^{11}$ Thus, Hood concludes, there is strong empirical support for the claim that mystical experiences have an identical core.

Further evidence comes from neurological studies, particularly the work of Andrew Newberg who became known as one of the founders of the field of neurotheology. Newberg's research has focused on brain activities during meditative and mystical states. One of his central findings is that during such states, metabolism in one region of the parietal lobe is significantly reduced, a region he has dubbed 'orientation association area' (OAA). ${ }^{12}$ The function of the OAA is to enable us to orient ourselves in physical space, which presupposes a clear distinction between everything which is part of ourselves and everything which is not. In other words, the OAA is the part of the brain which upholds the concept of an autonomous self. Reducing activity in this part of the brain will likely lead to a temporary cessation of its orientation function which might be an explanation for the sense of unity and dissolution of the self which mystics experience: if the brain has no more information on where the boundary between self and not-self lies, it will conclude that the self has no limits and that it expands infinitely into the universe, being one with everything. Newberg develops a detailed model of this process which is supposed to be a physiological explanation of the phenomenological quality of mystical experiences. ${ }^{13}$ More pertinent to the issue of the common core thesis, Newberg's research has shown that this neurological foundation is the same across different cultures and religions. Whether it is Buddhist monks in meditation or Franciscan nuns in contemplative prayer, the neural correlates of these states of mystical absorption are identical. ${ }^{14}$ SPECT scans of brains in these meditative states exhibit the same patterns of

\footnotetext{
9 See Hood (2001): 20ff. for more details.

${ }^{10}$ Hood (2006): 129.

11 Hood et al. (2001).

12 For an accessible summary of his research, see Newberg/d'Aquili (2001).

13 Newberg/d'Aquili (1999): chapter 6.

14 Newberg et al. (2003).
} 
decreasing activity in the OAA regardless of the religious beliefs the person has or the interpretation they give for their experience.

\section{The constructivist argument}

So, it seems as if there is good evidence for the common core thesis. But if there is a common core, what about the apparent differences? How can we claim that mystical experiences are essentially the same when in reality they differ quite a lot from each other? What is the common core (since the word 'core' is clearly used metaphorically here) and how can it be the same always and everywhere but also significantly different? In another context, Thomas Nagel once said that we can have good evidence that a physicalist theory of mind is true although we have no idea how it could be true. To actually understand it, we would need a conceptual framework in which we can explain what it means for physical states and mental states to be identical (just like the theory of relativity offers us a conceptual framework to make sense of the prima facie puzzling claim that matter is energy). We are in a similar situation with regard to the common core thesis: the available empirical evidence seems to point in the direction that it actually is true, but we still need a conceptual framework to explain how it can be true.

Usually, this framework is provided by introducing a distinction between the content of an experience and its interpretation: Interpretations may differ depending on the respective traditions, background beliefs, and conceptual schemes, but the core content is cognitively and phenomenologically the same. As, for example, Walter Stace puts it:

On a dark night out of doors one may see something glimmering white. One person may think it is a ghost. A second person may take it for a sheet hung out on a chlothesline. A third person may suppose that it is a white-painted rock. Here we have a single experience with three different interpretations. The experience is genuine, but the interpretations may be either true or false. ${ }^{15}$

The crucial point is, of course, whether the distinction between the content of an experience and its interpretation can actually be drawn, as the common core thesis suggests. Constructivists argue that it cannot - the distinction between content and interpretation is spurious. Experience, they claim, is always interpreted - the idea of an uninterpreted experience is nonsensical. For them, there is no point in talking about the 'content' of an experience as something detachable from its interpretation, because the experience is an indivisible whole. The distinction between content and experience suggests a picture of experience in which we first have some unprocessed raw mental content entering our mind which is then processed and interpreted by us. But, says the constructivist, the first and second step are one and the same. Experiencing something just is interpreting it. There is no such thing as a

15 Stace (1960): 10 . 
pure, uninterpreted mental content - a contradiction in terms. The most prominent defender of a constructivist approach to mystical experience is Stephen Katz. He writes:

There are NO pure (i.e. unmediated) experiences. [...] all experience is processed through, organized by, and makes itself available to us in extremely complex epistemological ways. The notion of unmediated experience seems, if not self-contradictory, at best empty. ${ }^{16}$

To counter this objection, we need to explain what the content of an experience is and how it can be detached from its interpretation. So, is there a way to maintain this distinction while at the same time respecting the fundamental unity of experience?

\section{The nonconceptual content of mystical experience}

What does it mean to interpret an experience? You might think of interpretation as an addition to experience: first, you have some experience, then you interpret it as an experience of this or that. Understood this way, interpretations are like beliefs about experiences, or hypotheses we form to explain them. In contrast, I want to suggest an account of interpretation inspired by Wittgenstein's idea of seeing-as or aspect-seeing. Wittgenstein gives the example of a drawing of a cube in a textbook which can - depending on the context - be seen as a box, a brick, or a wire frame: 'Each time the text supplies the interpretation of the illustration. But we can also see the illustration now as one thing, now as another. So we interpret it, and see it as we interpret it. ${ }^{, 17}$ Interpreting an experience in this sense simply means to see whatever I'm experiencing as something: I don't simply see the lines of the drawing, I see them as a box or brick. If I look at the summer sky, I don't just see something white and something blue, I see clouds in the sky, because I see the white stuff as clouds and the blue stuff as sky. This simply is seeing, not something separate from the act of seeing itself - 'to interpret is to think, to do something; seeing is a state', as Wittgenstein says ${ }^{18}$ — to see something as something, you don't have to do anything besides seeing. Interpretation understood as seeing-as (and not as hypothesizing) is ingrained into the experience itself. Now, Wittgenstein wanted to reserve seeing-as for puzzle cases like the famous duck-rabbit, where we can switch between seeing it as a duck and as a rabbit. He thought it absurd to say that you are seeing the thing in front of you on the table as a fork-you simply see a fork. But I believe that seeing-as is far more widespread than this-it is an essential part of all kinds of experiences. If you have never seen a fork before and have no idea what it is, you will be puzzled and ask: 'What is this thing?' If I then tell you that it is a fork, you will have gained little knowledge. But if I show you how to hold it and how to use it to pick up food, you will learn what a fork is. And when you see other forks on

\footnotetext{
16 Katz (1978): 26.

17 Wittgenstein (2009): 203 (PI pt. II, §116).

18 Wittgenstein (2009): 223 (PI pt. II, §248).
} 
another table, you will recognize them as forks. In other words, you have learned to see those things as forks.

And what is it you have learned when you learn to see something as a fork? You have learned the concept of a fork. Seeing-as means applying concepts to your experience. ${ }^{19}$ When I see the clouds in the sky, I see something as a cloud because I apply the concept 'cloud' to it. Again, seeing and conceptualizing are not two separate processes. The concept 'cloud' is part of the content of my experience, because it is impossible to describe my experience correctly without possessing the concept 'cloud' and employing it. If I see the clouds in the sky, this implies that I must possess the relevant concepts; otherwise, no such experience would be possible - I wouldn't be seeing clouds, only white stuff. So, interpretation is conceptualization. My experiences have conceptual (or representational) contents, similar to the contents of my beliefs (that's why we could say that I believe that there are clouds in the sky because I see the clouds in the sky), because in experiencing something, I am already seeing it as something. Given this account of interpretation, we might rephrase Katz' objection: every experience is an experience-as and is therefore necessarily conceptual in nature. There are no nonconceptual experiences.

Is this true? A lot of mental contents really are conceptual and this fact itself is neither surprising nor a problem. But constructivists rely on the much stronger claim that all experiences are conceptual, and this is far from obvious. Sure, if all experiences were conceptual, there could be no such thing as an experience without concepts-but there are at least some cases in which it seems possible to have experiences even if you don't possess the relevant concepts. For example, what about a young child who has not yet learned to speak? We wouldn't say that she is therefore unable to have experiences. The child may not yet have the concept of a teddy bear, but can still see the teddy bear, touch it, or want to have it. The teddy bear is the object of her experience, even though she doesn't see the teddy bear as teddy bear, since this would require her to have this particular concept. She can't subsume a multitude of different objects under the concept 'teddy bear' and recognize them as instantiations of this concept—she won't understand that Freddy, Bobby, and Bruno are teddy bears. So, the child will not know that she is seeing a teddy bear, but not knowing that you are seeing something is not the same as not seeing it at all. She is seeing a teddy bear, but not as a teddy bear: her experience therefore has a nonconceptual content. ${ }^{20}$ On the one hand, her experience represents reality, since it has correctness conditions: her representation of the teddy bear may be true to the facts or not, even though it is not true or false in a technical sense (it has no propositional content and therefore cannot have a truth value). On the other hand, she doesn't possess the relevant concepts we, as observers, would need to describe her experience. Whether the content of an experience is conceptual or not, depends on the subject: 'to say that a mental content is nonconceptual is to say that its subject need not possess any of the concepts that we, as theorists, exercise when we state the correctness

\footnotetext{
${ }^{19}$ For a defense of the thesis that seeing-as is best understood as conceptualization, see Agam-Segal (2014).

20 This account of nonconceptual content is based on Crane (1992): 138ff.
} 
conditions for that content. ${ }^{21}$ One and the same thing can thus be experienced conceptually by one subject and nonconceptually by another. So, it seems to be at least possible for an experience to have a nonconceptual content, and the constructivist objection fails. But, the constructivist might reply, this only holds for non-linguistic beings - of course, their experiences don't have conceptual contents. But what if a being has already learned to speak?

Consider the following example: two people, Zhou and Joe, see the following text: 道可道非常道. Zhou speaks Chinese, Joe doesn't. They are both capable of seeing the characters and in a way, both of them see the same thing; they have the same visual impression. Learning to read won't make you see something other than before (it won't change anything about your eyesight). But in another, equally important way, they don't see the same. Zhou sees characters and a text and will understand them, but all that Joe sees is a certain pattern of black strokes on a white background. Of course, Joe does see the characters, too. But he doesn't see them as characters (he may not even recognize them as some kind of script) - but again, not knowing that one is seeing something is not the same as not seeing it at all. How can we make sense of this: they see and don't see the same thing? Obviously, the sameness is rooted in the sensual contents of their experiences (they see the same thing), while the differences stem from the concepts available to them (they don't see it as the same thing). So, it seems as if the content of Zhou's experience is conceptual, while the content of Joe's experience is not. Joe's experience still represents reality and has correctness conditions. It's just that he doesn't possess the concepts we need to explicate these correctness conditions. As we noted above, whether some content is conceptual or not depends on the subject having the experience, not on the content itself. The same object is experienced conceptually by Zhou while Joe experiences it nonconceptually. Both of them see the black ink on a white background, but Zhou possesses the relevant concepts to understand the ink pattern and Joe does not. They interpret their experience differently because only Zhou is able to correctly conceptualize it.

One might object that this doesn't prove the point yet: Why must Joe's experience be nonconceptual? Couldn't he be using other (perhaps less suitable) concepts than Zhou, like 'black strokes' or 'six characters'? Then he's not really having a nonconceptual experience, just a regular old conceptual one with different concepts. His experience is interpreted, too, just not in a very sophisticated manner.

Let's take a look at the famous duck-rabbit again. We can see this picture differently, either as a duck or as a rabbit which means we can switch the concepts through which we interpret our experience. The picture itself doesn't change at all. But what is it that remains unchanged during this switch from seeing a rabbit to seeing a duck? The switch is a conceptual change-if you possess the concept of a duck, but not a rabbit, you will never see the rabbit. So, there has to be something which is conceptualized or seen as something - and this is the non- or preconceptual content. The mere idea of conceptualization presupposes something which is conceptualized and which we may call 'nonconceptual content', even if this

${ }^{21}$ Tye (2000): 62. 
content cannot exist apart from the conceptual experience (and therefore is not a pure 'given', or raw content). But our constructivist might still not be convinced: Alright, she replies, but where is this supposed nonconceptual experience? Whatever we see, be it a duck or a rabbit, we see something - not just the black lines. Even if we accept that the same experience can be shaped differently by applying different concepts, nothing is experienced nonconceptually. All we have is two different conceptual experiences. There is no nonconceptual content-and therefore no uninterpreted experience.

But this objection confuses a constant connection with logical necessity. For even if all experiences are always conceptually interpreted, it still doesn't follow that experience is necessarily conceptual, simply because a constant connection of two properties is not the same as a conceptual necessity. For example, all triangles we will ever encounter are made of some kind of matter: ink or wood, bricks or pixels. We will never see a non-material triangle. That still doesn't mean that being made out of matter is an essential property of triangles or that a definition of triangles must include their material nature. In fact, our concept of a triangle pays no attention to its material aspect at all; we can perfectly well explain what a triangle is without referring to any material properties. The same holds for nonconceptual content: even if all of our experiences have as a matter of fact conceptual content, it still doesn't follow that the idea of a nonconceptual content is self-defeating. It could, after all, be something we can conceive of, but can never encounter in reality.

But why do we need this ominous nonconceptual content if all content is as a matter of fact conceptual? The answer is: to explain the content of an experience itself. Nonconceptual content is not a further kind of experiential content, it is an aspect of it. When we theorize about the contents of experience, we need to postulate it to explain how conceptual content works at all. Therefore, the non- or preconceptual core itself need not be experienced at all. The constructivist may well be right about the fact that in the duck-rabbit case, we have two different conceptual experiences, but that's not what matters. It doesn't matter if it is actually possible to experience something nonconceptually or not. All that matters is that we can logically distinguish between the conceptual content of an experience and the nonconceptual content which is conceptualized in that experience. This distinction allows us to understand what's happening in the duck-rabbit example: while seeing one and the same thing (nonconceptually) we switch between different modes of seeing-as, which means that the pre- or nonconceptual aspect of the experiential content is conceptualized differently. The common core of duck and rabbit is an abstraction that is never experienced purely by itself. But we can infer its existence through reflection, if not through experience. When we look at Wittgenstein's duck-rabbit, we always see either a duck or a rabbit, but still both experiences have a common core: the black lines. It may be impossible to see just these black lines and not see them as anything, to see the picture not as a picture of something but as 
some kind of pure shape, ${ }^{22}$ but that still doesn't mean that this common core doesn't exist. Likewise, the common core of mystical experiences is itself not an experience (be it conceptual or not), it is something we abstract and derive from the actual (conceptual) experiences in order to explain what they have in common and how it is possible for two people to have the same experience and yet see something different.

Then what about Katz' original statement? ('There are no pure, unmediated experiences'?) It may well be true, if we understand it correctly. If it means that all experiences involve concepts and that there are no purely nonconceptual experiences (for linguistic beings), then we may accept it. But this doesn't rule out the idea that to explain the nature of experience and duck-rabbit cases, we need to postulate a pre-conceptual content that is not experienced separately, in itself. So, Katz is right. Mystical experiences are shaped by certain preexisting concepts and cannot be separated from the religious tradition they grow out of. But this still leaves room for a common core embedded in the conceptual experience. The common core is not itself an experience (and so the experiences need not be phenomenologically identical in a strict sense) - it is only an aspect of various experiences. Nobody may experience the core. The common core is an object for philosophers, not mystics. It's an explanatory hypothesis, not an object of experience. Still, it is there.

Consequently, it isn't a problem that actual mystical experiences are always shaped by those beliefs and concepts the mystics bring with them. Those beliefs and concepts shape their whole religious life and thought—why should their mystical experiences be any different? But it doesn't follow that each tradition has a type of experience so unique that these experiences can only be understood from within or that it is impossible to compare them with other traditions. The common core thesis doesn't claim that our background beliefs and concepts are irrelevant for our experiences-they surely are. It's just that they alone don't constitute these experiences. Yes, there is a real diversity in mystical experiences which results from the various cultural boundary conditions. But that doesn't preclude us from assuming that there is a nonconceptual core to these experiences, unaffected by our concepts and beliefs, discoverable only by reflection, and subject to multiple interpretations depending on the various cultural contexts.

Funding Open Access funding enabled and organized by Projekt DEAL.

Open Access This article is licensed under a Creative Commons Attribution 4.0 International License, which permits use, sharing, adaptation, distribution and reproduction in any medium or format, as long as you give appropriate credit to the original author(s) and the source, provide a link to the Creative Commons licence, and indicate if changes were made. The images or other third party material in this article are included in the article's Creative Commons licence, unless indicated otherwise in a credit line to the material. If material is not included in the article's Creative Commons licence and your intended use is not permitted by statutory regulation or exceeds the permitted use, you will need to obtain permission directly from the copyright holder. To view a copy of this licence, visit http://creativecommons.org/licen ses/by/4.0/.

\footnotetext{
22 One hypothesis is that this is exactly what happens in mystical experiences. See e.g. Forman (1999) who understands mystical experiences as pure conscious events in which all conceptual thinking ceases and pure nonconceptual awareness remains.
} 


\section{References}

Agam-Segal, Reshef. (2014). When language gives out. Conceptualization, and aspect-seeing as a form of judgement. Metaphilosophy, 45, 41-68

Alston, W. (1991). Perceiving God. Cornell University Press.

Crane, Tim: The nonconceptual content of experience. In: Crane, Tim (ed.): The Contents of Experience. Essays in Perception. Cambridge: Cambridge University Press, 1992, 136-157.

Davies, Brian: An Introduction to the philosophy of religion. Oxford: Oxford University Press, ${ }^{3} 2004$.

Davis, F. (1989). Caroline: The evidential force of religious experience. Clarendon.

Flew, A. (2005). God and Philosophy. Prometheus Books.

Forman, R. (1999). Mysticism, mind, consciousness. SUNY Press.

Hick, John: An interpretation of religion. Basingstoke: Palgrave Macmillan, ${ }^{2} 2004$.

Hood, Ralph et al.: Dimensions of the mysticism M-scale: Confirming the three factor structure in the United States and Iran. Journal for the Scientific Study of Religion 40 (2001), 691-705.

Hood, R. (2001). Dimensions of mystical experience. Rodopi.

Hood, Ralph: The common core thesis in the study of mysticism. In: Patrick McNamara (Hg.): Where God and Science meet. Bd. III: The psychology of religious experience. Westport: Praeger, 2006, 119-138.

James, William: The varieties of religious experience. London: Routledge, 2002 [1902].

Katz, Stephen: Language, epistemology, and mysticism. Katz, Stephen (Hg.): Mysticism and philosophical analysis. Oxford: Oxford University Press, 1978, 22-74.

Marshall, P. (2005). Mystical encounters with the natural world. Oxford University Press.

Newberg, Andrew et al.: Cerebral Blood Flow during Meditative Prayer: Preliminary Findings and Methodological Issues. In: Perceptual and Motor Skills 97 (2003), 625-630.

Newberg, A., \& d'Aquili, E. (1999). The mystical mind. Fortress Press.

Newberg, Andrew/d'Aquili, Eugene: Why God won't go away. Brain science and the biology of belief. New York: Ballantine, 2001.

Stace, W. (1960). The teachings of the mystics. New American Library.

Stace, W. (1961). Mysticism and Philosophy. Macmillan.

Swinburne, Richard: The existence of God. Oxford: Oxford University Press, ${ }^{2} 2004$.

Tye, M. (2000). Consciousness, Color, and Content. MIT Press.

Wainwright, W. (1981). Mysticism. Harvester Press.

Wittgenstein, Ludwig: Philosophische Untersuchungen. Philosophical investigations. Oxford: WileyBlackwell, ${ }^{4} 2009$.

Yandell, K. (1993). The epistemology of religious experience. Cambridge University Press.

Publisher's Note Springer Nature remains neutral with regard to jurisdictional claims in published maps and institutional affiliations. 